\title{
Strongly $b^{*}$ - Continuous Functions in Topological Spaces
}

\author{
A.Poongothai and R.Parimelazhagan \\ Department of Science and Humanities, \\ Karpagam College of Engineering, \\ Coimbatore-32.Tamil Nadu, India
}

\begin{abstract}
In this paper, we present and study a new generation of strongly $b^{*}$-continuous functions. Furthermore, we obtain basic properties and preservation theorems of strongly $b^{*}$ - continuous functions and relationships between them. Also we studied the strongly $b^{*}$ - open and closed maps.
\end{abstract}

\section{General Terms}

2000 Mathematics Subject Classification: 54C05, 54C10.

\section{Keywords}

strongly $\mathrm{b}^{*}$ - continuous functions, strongly $\mathrm{b}^{*}$-open maps and closed maps.

\section{INTRODUCTION}

Levine[11] introduced the concept of generalized closed sets in topological spaces and a class of topological spaces called $\mathrm{T}_{1 / 2}$ - spaces. Dunham[7] and Dunham and Levine [8] further studied some properties of generalized closed sets and $T_{1 / 2}$ - spaces. Strong forms of continuous maps have been introduced and investigated by several mathematicians. strongly continuous maps, perfectly continuous maps, completely continuous maps, clopen continuous maps were introduced by Levine[13], Noiri[18], Munshi and Bassan[15] and Reilly and Vamanamurthy[20] respectively. Semi continuous functions have been studied by several authors. Dontchev[5], Ganster and Reilly[6] introduced contracontinuous functions and regular set - connected functions. Erdal Ekici [9] introduced and studied a new class of functions called almost contra-pre- continuous functions which generalize classes of regular set connected [6], contra- pre continuous [11], contra continuous [5], almost s - continuous [17] and perfectly continuous functions [18]. In this paper, we introduce and study the strongly $\mathrm{b}^{*}$ - continuous functions in topological spaces. Also we studied the strongly $b^{*}$ - open and closed maps.

\section{PRELIMINARIES}

In this section, we begin by recalling some definitions

Definition 2.1[21]: A map f: $\mathrm{X} \rightarrow \mathrm{Y}$ from a topological space $\mathrm{X}$ into a topological space $\mathrm{Y}$ is called semi-generalized continuous (sg-continuous) if $\mathrm{f}^{-1}(\mathrm{~V})$ is sg- closed in $\mathrm{X}$ for every closed set $\mathrm{V}$ of $\mathrm{Y}$.

Definition 2.2[3]: A map f: $\mathrm{X} \rightarrow \mathrm{Y}$ is semi-continuous if and only if for every closed set $\mathrm{B}$ of $\mathrm{Y}, \mathrm{f}^{-1}(\mathrm{~B})$ is semi-closed in $\mathrm{X}$.
Definition 2.3[2]: A function $\mathrm{f}: \mathrm{X} \rightarrow \mathrm{Y}$ is said to be generalized continuous (g-continuous) if $f^{-1}(V)$ is g-open in $\mathrm{X}$ for each open set $\mathrm{V}$ of $\mathrm{Y}$.

Definition 2.4[10]: A function $\mathrm{f}: \mathrm{X} \rightarrow \mathrm{Y}$ is said to be $\mathrm{b}$-continuous if for each $\mathrm{x} \in \mathrm{X}$ and for each open set of $\mathrm{V}$ of $Y$ containing $f(x)$, there exists $U \in b O(X, x)$ such that $\mathrm{f}(\mathrm{U}) \subseteq \mathrm{V}$.

Definition 2.5[22]: A function $\mathrm{f}: \mathrm{X} \rightarrow \mathrm{Y}$ is said to be $\mathrm{W}$-continuous if $\mathrm{f}^{-1}(\mathrm{~V})$ is $\mathrm{W}$ - open in $\mathrm{X}$ for each open set $\mathrm{V}$ of Y.

Definition: 2.6 [14]: A function $\mathrm{f}: \mathrm{X} \rightarrow \mathrm{Y}$ is said to be $\alpha$-continuous if $\mathrm{f}^{-1}(\mathrm{~V})$ is $\alpha$-open in $\mathrm{X}$ for each open set $\mathrm{V}$ of $\mathrm{Y}$.

Definition: 2.7 [16]: Let $\mathrm{X}$ and $\mathrm{Y}$ be topological spaces. A map $\mathrm{f}: \mathrm{X} \rightarrow \mathrm{Y}$ is said to be weakly generalized continuous (wg-continuous) if the inverse image of every open set in $\mathrm{Y}$ is wg-open in $\mathrm{X}$.

Definition 2.8:[4] A function $\mathrm{f}: \mathrm{X} \rightarrow \mathrm{Y}$ is said to be $\alpha \mathrm{g}$ - continuous if $\mathrm{f}^{-1}(\mathrm{~V})$ is $\alpha \mathrm{g}$ - open in $\mathrm{X}$ for each open set $\mathrm{V}$ of $\mathrm{Y}$.

Definition 2.9[1]: A map $\mathrm{f}: \mathrm{X} \rightarrow \mathrm{Y}$ is semi precontinuous if and only if for every closed set $\mathrm{B}$ of $\mathrm{Y}, \mathrm{f}^{-1}$ (B)is semi pre-closed in X.

Definition 2.10[19]: A subset $A$ of a topological space $(X, \tau)$ is called a strongly $b^{*}$ - closed set (briefly $s b^{*}$ - closed) if din $(A)) \subseteq U$ whenever $A \subseteq U$ and $U$ is $b$ open in $\mathrm{X}$.

\section{STRONGLY $b^{*}$ - CONTINUOUS FUNCTIONS}

In this section, we introduce the new class of definition $\mathrm{sb}^{*}$-continuous function in topological space. Also we discuss some of its properties.

Definition 3.1: Let $X$ and $Y$ be topological spaces. A map $\mathrm{f}: \mathrm{X} \rightarrow \mathrm{Y}$ is called strongly $\mathrm{b}^{*}$ - continuous ( $\mathrm{sb}^{*}$ - continuous) if the inverse image of every open set in $\mathrm{Y}$ is sb* - open in $\mathrm{X}$.

Theorem 3.2: If a map $\mathrm{f}: \mathrm{X} \rightarrow \mathrm{Y}$ is continuous then it is $\mathrm{sb}^{*}$ - continuous but not conversely.

Proof: Let $\mathrm{f}: \mathrm{X} \rightarrow$ Y be continuous. Let Fbe any open set in $\mathrm{Y}$. The inverse image of $F$ is open in $X$. Since every open set is $\mathrm{sb}^{*}$-open set, inverse image of $\mathrm{F}$ is $\mathrm{sb}^{*}$ - open set in $\mathrm{X}$. Therefore $\mathrm{f}$ is $\mathrm{sb}^{*}$ - continuous.

Remark 3.3: The converse of the above theorem need not be true as seen from the following example. 
Example 3.4: Consider $X=\{1,2,3\}$ with $\tau=\{X$, $\varphi,\{1,3\}\}, Y=\{a, b, c\}$ and $\sigma=\{Y, \varphi,\{b\},\{a, c\}\}$. Let $\mathrm{f}:(\mathrm{X}, \tau) \rightarrow(\mathrm{Y}, \sigma)$ be defined by $\mathrm{f}(1)=\mathrm{a}, \mathrm{f}(3)=\mathrm{b}, \mathrm{f}(2)=\mathrm{c}$. Then $\mathrm{f}$ is $\mathrm{sb}^{*}$-continuous. But $\mathrm{f}$ is not continuous since for the open set $U=\{a, c\}$ in $Y, f^{-1}(U)=\{1,2\}$ is not open in $X$.

Theorem 3.5: Let $\mathrm{f}:(\mathrm{X}, \tau) \rightarrow(\mathrm{Y}, \sigma)$ be a map from a topological space $(\mathrm{X}, \tau)$ in to a topological space $(\mathrm{Y}, \sigma)$. The statement (a) $\mathrm{f}$ is sb* - continuous is equivalent to the statement (b) the inverse image of each open set in $\mathrm{Y}$ is $\mathrm{sb}^{*}$-open in $\mathrm{X}$.

Proof: Assume that $\mathrm{f}: \mathrm{X} \rightarrow \mathrm{Y}$ is sb*-continuous. Let $\mathrm{G}$ be open in $Y$. Then $G^{c}$ is closed in $Y$. Since $f$ is $\mathrm{sb}^{*}$-continuous, $\mathrm{f}^{-1}\left(\mathrm{G}^{9}\right)$ is $\mathrm{sb}^{*}$-closed in $\mathrm{X}$. But $\mathrm{f}^{-1}\left(\mathrm{G}^{\mathrm{g}}\right)=\mathrm{X}$ $\mathrm{f}^{-1}(\mathrm{G})$. Thus $\mathrm{X}-\mathrm{f}^{-1}(\mathrm{G})$ is sb*-closed in $\mathrm{X}$ and so $\mathrm{f}^{-1}(\mathrm{G})$ is sb*-open in $X$. Therefore $(\mathrm{a}) \Rightarrow$ (b)

Conversely, assume that the inverse image of each open set in $\mathrm{Y}$ is $\mathrm{sb}^{*}$ - open in $\mathrm{X}$. Let $\mathrm{F}$ be any closed set in $\mathrm{Y}$. Then $\mathrm{f}^{-1}\left(\mathrm{~F}^{\mathrm{c}}\right)$ is sb $\mathrm{sb}^{*}$ - open in $\mathrm{X}$. But $\mathrm{f}^{-1}(\mathrm{~F})=\mathrm{X}-\mathrm{f}^{-1}(\mathrm{~F})$. Thus $\mathrm{X}$ $\mathrm{f}^{-1}(\mathrm{~F})$ is $s b^{*}-$ open in $\mathrm{X}$ and so $\mathrm{f}^{-1}(\mathrm{~F})$ is $s b^{*}$-closed in $\mathrm{X}$. Therefore $\mathrm{f}$ is $\mathrm{sb}^{*}$-continuous. Hence (b) $\Rightarrow$ (a). Thus (a) and (b) are equivalent.

Theorem 3.6: Let $\mathrm{f}: \mathrm{X} \rightarrow \mathrm{Y}$ be a sb*-continuous map from a topological space $\mathrm{X}$ in to a topological space $\mathrm{Y}$ and let $\mathrm{H}$ be a closed subset of $\mathrm{X}$. Then the restriction $\mathrm{f} / \mathrm{H}: \mathrm{H} \rightarrow$ $\mathrm{Y}$ is $\mathrm{sb}^{*}$ - continuous where $\mathrm{H}$ is endowed with the relative topology.

Proof: Let $F$ be any closed subset in Y. Since $f$ is $\mathrm{sb}^{*}$ - continuous, $\mathrm{f}^{-1}(\mathrm{~F})$ is $\mathrm{sb}^{*}$ - closed in $\mathrm{X}$. Intersection of $\mathrm{sb}^{*}$-closed sets is $\mathrm{sb}^{*}$ - closed set. Thus if $\mathrm{f}^{-1}(\mathrm{~F}) \cap \mathrm{H}=\mathrm{H}_{1}$ then $H_{1}$ is $s b^{*}$ - closed set in $X$. Since $(f / H)^{-1}(F)=H_{1}$, it is sufficient to show that $\mathrm{H}_{1}$ is sb* - closed set in $\mathrm{H}$. Let $\mathrm{G}_{1}$ be any open set of $H$ such that $H_{1} \subset G_{1}$. Let $G_{1}=G \cap H$ where $\mathrm{G}$ is open in $\mathrm{X}$. Now $\mathrm{H}_{1} \subset \mathrm{G} \cap \mathrm{H} \cap \mathrm{G}$. Since $\mathrm{H}_{1}$ is sb* - closed in $\mathrm{X}, \overline{H_{1}} \subset G$. Now $c_{H}\left(H_{1}\right)=\overline{\mathrm{H}_{1}} \cap H \subset G \cap H=G_{1}$, where $\mathrm{cl}_{H}(\mathrm{~A})$ is the closure of a subset $\mathrm{A} \subset \mathrm{H}$ in a subspace $\mathrm{H}$ of $\mathrm{X}$. Therefore $\mathrm{f} / \mathrm{H}$ is $\mathrm{sb}^{*}$ - continuous.

Remark 3.7: In the above theorem, the assumption of closedness of $\mathrm{H}$ cannot be removed as seen from the following example.

Example 3.8: Let $\mathrm{X}=\{\mathrm{a}, \mathrm{b}, \mathrm{c}\}, \tau=\{X, \varphi,\{b\}\}, \mathrm{Y}$ $=\{\mathrm{p}, \mathrm{q}\}$ and $\sigma=\{Y, \varphi,\{p\}\}$. Let $\mathrm{f}:(\mathrm{X}, \tau) \rightarrow(\mathrm{Y}, \sigma)$ be defined by $\mathrm{f}(\mathrm{a})=\mathrm{f}(\mathrm{c})=\mathrm{q}, \mathrm{f}(\mathrm{b})=\mathrm{p}$. Now $\mathrm{H}=\{\mathrm{a}, \mathrm{b}\}$ is not closed in $\mathrm{X}$. Then $\mathrm{f}$ is $\mathrm{sb}^{*}$ - continuous but the restriction $\mathrm{f} / \mathrm{H}$ is not $\mathrm{sb}^{*}$-continuous. Since for the closed set $\mathrm{F}=\{\mathrm{q}\}$ in $\mathrm{Y}$, $\mathrm{f}^{-1}(\mathrm{~F})=\{\mathrm{a}, \mathrm{c}\}$ and $\mathrm{f}^{-1}(\mathrm{~F}) \cap \mathrm{H}=\{\mathrm{a}\}$ is not sb*-closed in $\mathrm{H}$.

Theorem 3.9: A map $\mathrm{f}: \mathrm{X} \rightarrow \mathrm{Y}$ is $\mathrm{sb}^{*}$ - continuous if and only if the inverse image of every closed set in $\mathrm{Y}$ is $\mathrm{sb}^{*}$. closed in $\mathrm{X}$

Proof: Let $\mathrm{F}$ be a closed set in $\mathrm{Y}$. Then $\mathrm{F}^{c}$ is open in $\mathrm{Y}$. Since $\mathrm{f}$ is $\mathrm{sb}^{*}$-continuous, $\mathrm{f}^{-1}(\mathrm{~F})$ is $\mathrm{sb}^{*}$ - open in $\mathrm{X}$. But $\mathrm{f}^{-1}(\mathrm{~F} c)=\mathrm{X}-\mathrm{f}^{-1}(\mathrm{~F})$ and $\operatorname{sof}^{-1}(\mathrm{~F})$ is sb* $\mathrm{s}^{*}$ closed in $\mathrm{X}$.

Conversely, let the inverse image of every closed set in $\mathrm{Y}$ is sb* - closed set in $\mathrm{X}$. Let $\mathrm{V}$ be an open set in $\mathrm{Y}$ and $\mathrm{V}^{c}$ is closed in $\mathrm{Y}$. Now by the assumption $\mathrm{f}^{-1}(\mathrm{~V} c)=\mathrm{X}$ -
$\mathrm{f}^{-1}(\mathrm{~V})$ is s $\mathrm{b}^{*}$ - closed set in $\mathrm{Y}$. Therefore $\mathrm{f}^{-1}(\mathrm{~V})$ is $\mathrm{sb}^{*}$ - open in $\mathrm{X}$. Then $\mathrm{f}$ is $\mathrm{sb}^{*}$ - continuous.

Theorem 3.10: If a function $\mathrm{f}: \mathrm{X} \rightarrow \mathrm{Y}$ is sb*-continuous then it is b-continuous but not conversely.

Proof: Assume that a map $\mathrm{f}: \mathrm{X} \rightarrow \mathrm{Y}$ is $\mathrm{sb}^{*}$ - continuous. let $\mathrm{V}$ be an open set in $\mathrm{Y}$. Since $\mathrm{f}$ is $\mathrm{sb}^{*}$ - continuous $\mathrm{f}^{-}$ $(\mathrm{V})$ is $\mathrm{sb}^{*}$-open and hence $\mathrm{b}$ - open in $\mathrm{X}$. Therefore $\mathrm{f}$ is $\mathrm{b}$ continuous

Remark 3.11: The converse of the above theorem need not be true as seen from the following example.

Example 3.12: Let $X=Y=\{a, b, c\}$ with $\tau=\{X$, $\varphi,\{a\},\{c\},\{a, c\}\} \quad, \quad \sigma=\{Y, \quad \varphi,\{b\},\{c\},\{b, c\}\}$ and $\mathrm{f}=\{(\mathrm{a}, \mathrm{b}),(\mathrm{b}, \mathrm{b}),(\mathrm{c}, \mathrm{c})\}$. Then $\mathrm{f}$ is $\mathrm{b}$-continuous but not $\mathrm{sb}^{*}$-continuous. Since the inverse image of the open set $\{b\}$ in $Y$ is $\{a, b\}$ in $X$ is not $s^{*}$ - open.

Theorem 3.13: If a map f: $\mathrm{X} \rightarrow \mathrm{Y}$ is $\alpha$-continuous then it is $\mathrm{sb}^{*}$-continuous but not conversely.

Proof: Assume that $\mathrm{f}$ is $\alpha$-continuous. Let $\mathrm{V}$ be an open set in $\mathrm{Y}$. Since $\mathrm{f}$ is $\alpha$-continuous, $\mathrm{f}^{-1}(\mathrm{~V})$ is $\alpha$-open and hence it is $\mathrm{sb}^{*}$-open in $\mathrm{X}$. Then $\mathrm{f}$ is $\mathrm{sb}^{*}$-continuous.

Remark 3.14: The converse of the above theorem be true as seen from the following example.

Example 3.15: Let $\mathrm{X}=\mathrm{Y}=\{\mathrm{a}, \mathrm{b}, \mathrm{c}\}$ with $\tau=\{X$, $\varphi,\{b\},\{a, c\}\}$ and $\sigma=\{Y, \varphi,\{a, c\}\}$. Consider $\mathrm{f}: \mathrm{X} \rightarrow \mathrm{Y}$ which is defined as $\mathrm{f}(\mathrm{a})=\mathrm{f}(\mathrm{b})=\mathrm{b}, \mathrm{f}(\mathrm{c})=\mathrm{c}$. This function $\mathrm{f}$ is

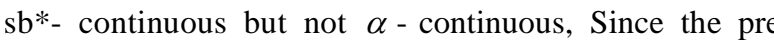
image of the open set $\{\mathrm{a}, \mathrm{c}\}$ in $\mathrm{Y}$ is $\{\mathrm{c}\}$ in $\mathrm{X}$ is not $\alpha$-open.

Theorem 3.16: If a map $\mathrm{f}: \mathrm{X} \rightarrow \mathrm{Y}$ is $\mathrm{sb}^{*}$-continuous then it is wg-continuous but not conversely.

Proof: Assume that a map $\mathrm{f}: \mathrm{X} \rightarrow \mathrm{Y}$ is $\mathrm{sb}^{*}$ - continuous Let $\mathrm{V}$ be an open set in $\mathrm{Y}$. Since $\mathrm{f}$ is $\mathrm{sb}^{*}$ - continuous, $\mathrm{f}^{-1}(\mathrm{~V})$ is sb*-open and hence it is wg-open in $\mathrm{X}$. Then $\mathrm{f}$ is wgcontinuous.

Remark 3.17: The converse of the above theorem need not be true as seen from the following exampl

Example 3.18: $\quad$ Let $\mathrm{X}=\mathrm{Y}=\square\{\mathrm{a}, \mathrm{b}, \mathrm{c}\}$ with $\tau=\square\{\mathrm{X}$, $\varphi, \square\{\mathrm{b}\}\}$ and $\sigma=\square\{\mathrm{Y}, \varphi, \square\{\mathrm{a}\}, \square\{\mathrm{a}, \mathrm{b}\}\}$ and $\mathrm{f}$ be the identity map. Then $\mathrm{f}$ is wg-continuous but not $\mathrm{sb}^{*}$ continuous, as the inverse image of the open set $\square\{a\} \square$ in $\mathrm{Y}$ is $\square\{\mathrm{a}\}$ in $\mathrm{X}$ is not sb*- open.

Theorem 3.19: If a map $\mathrm{f}: \mathrm{X} \rightarrow \mathrm{Y}$ is w-continuous then it is $\mathrm{sb}^{*}$ - continuous but not conversely.

Proof: Let $\mathrm{f}: \mathrm{X} \rightarrow \mathrm{Y}$ is w-continuous and $\mathrm{V}$ be an open set in $Y$ then $f^{-1}(V)$ is $w$ - open and hence sb*-open in $X$. Then $f$ is $\mathrm{sb}^{*}$ - continuous. The converse of the above theorem need not be true as seen from the following example.

Exmple 3.20: Let $X=Y=\{a, b, c\}$ with $\tau=\{X, \varphi,\{b\}\}$ and $\sigma=\{Y, \varphi,\{b, c\}\}$ and $\mathrm{f}$ be the identity map. Then $\mathrm{f}$ is $\mathrm{sb}^{*}$ - continuous but not w-continuous, as the inverse image of the open set $\{b, c\}$ in $\mathrm{Y}$ is $\{\mathrm{b}, \mathrm{c}\}$ in $\mathrm{X}$ is not w- open. 
Theorem 3.21: If a map $\mathrm{f}: \mathrm{X} \rightarrow \mathrm{Y}$ is sb*-continuous then it is semi pre continuous but not conversely

Proof: Let $\mathrm{f}: \mathrm{X} \rightarrow \mathrm{Y}$ is sb*-continuous and $\mathrm{V}$ be an open set in $\mathrm{Y}$ then $\mathrm{f}^{-1}(\mathrm{~V})$ is sb*-open set and hence semi pre open set in $\mathrm{X}$. Then $\mathrm{f}$ is semi pre continuous.

Remark 3.22: The converse of the above theorem need not be true as seen from the following example.

Example 3.23: Let $\mathrm{X}=\mathrm{Y}=\{\mathrm{a}, \mathrm{b}, \mathrm{c}\}$ with $\tau=\{X$, $\varphi,\{a\},\{c\},\{a, c\}\}$ and $\sigma=\{Y, \varphi,\{b, c\}\}$ and $\mathrm{f}$ be the identity map. Then $f$ is semi pre continuous but not $\mathrm{sb}^{*}$ - continuous, since the inverse image of the open set $\{b, c\}$ in $Y$ is $\{b, c\}$ in $X$ is not $s b^{*}$ - open

Remark 3.24: From the above results the diagram follows:

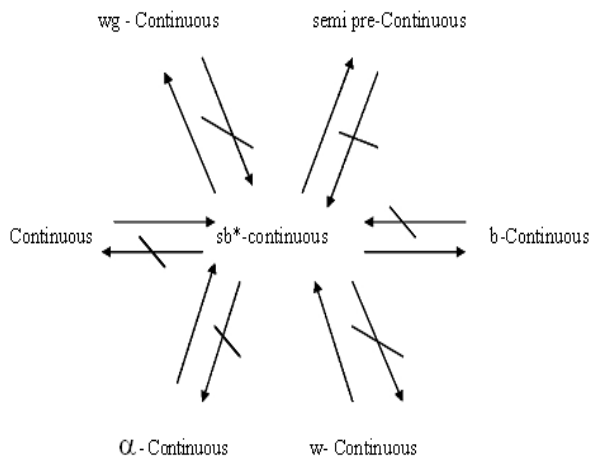

Remark 3.25: The following example shows that the gcontinuous function and $\mathrm{sb}^{*}$ - continuous function are independent.

Example 3.26: Consider $\mathrm{X}=\mathrm{Y}=\{\mathrm{a}, \mathrm{b}, \mathrm{c}\}$ with $\tau=\{X$, $\varphi,\{b\}\}$ and $\sigma=\{Y, \varphi,\{a\},\{b, c\}\}$. Let the function $\mathrm{f}:(\mathrm{X}, \tau) \rightarrow(\mathrm{Y}$, $\sigma)$ be defined by $\mathrm{f}(\mathrm{a})=\mathrm{b}, \mathrm{f}(\mathrm{b})=\mathrm{c}, \mathrm{f}(\mathrm{c})=\mathrm{a}$. This function $\mathrm{f}$ is g- continuous but not $\mathrm{sb}^{*}$ - continuous since the inverse image of the open set $\{a\}$ in $\mathrm{Y}$ is $\{\mathrm{c}\}$ in $\mathrm{X}$ is not $\mathrm{sb}^{*}$ open.

Example 3.27: Consider $\mathrm{X}=\mathrm{Y}=\{\mathrm{a}, \mathrm{b}, \mathrm{c}\}$ with $\tau=\{X$, $\varphi,\{a\},\{a, b\}\}$ and $\sigma=\{Y, \varphi,\{a, b\}\}$. Let the function $\mathrm{f}:(\mathrm{X}, \tau) \rightarrow$ $(\mathrm{Y}, \sigma)$ be defined by $\mathrm{f}(\mathrm{a})=\mathrm{f}(\mathrm{c})=\mathrm{b}$ and $\mathrm{f}(\mathrm{b})=\mathrm{c}$. Here the inverse image of the open set $\{a, b\}$ in $Y$ is $\{a, c\}$ in $X$ which is $\mathrm{sb}^{*}$ - open but not $\mathrm{g}$ - open. Therefore this function is $\mathrm{sb}^{*}$ - continuous but not g-continuous

Remark 3.28: The following example shows that the $\alpha \mathrm{g}$ - continuous function and $\mathrm{sb}^{*}$ - continuous function are independent.

Example 3.29: Consider $X=Y=\{a, b, c\}$ with $\tau=\{X, \varphi,\{b\}\}$ and $\sigma=\{Y, \varphi,\{c\}\}$. Let the function $\mathrm{f}:(\mathrm{X}, \tau) \rightarrow(\mathrm{Y}$, $\sigma$ ) be defined by $\mathrm{f}(\mathrm{a})=\mathrm{a}, \mathrm{f}(\mathrm{b})=\mathrm{b}, \mathrm{f}(\mathrm{c})=\mathrm{c}$. Here the inverse image of the open set $\{c\}$ in $\mathrm{Y}$ is $\{\mathrm{c}\}$ in $\mathrm{X}$ which is $\alpha \mathrm{g}$ open set but not sb* - open. Therefore the defined function is $\alpha \mathrm{g}$ - continuous but not $\mathrm{sb}^{*}$-continuous.
Example 3.30: Consider $\mathrm{X}=\mathrm{Y}=\{\mathrm{a}, \mathrm{b}, \mathrm{c}\}$ with $\tau=\square\{$ $X, \varphi, \square\{a\},\{a, b\}\}$ and $\sigma=\square\{Y, \varphi, \square\{a, c\}\}$. Let the function $\quad \mathrm{f}:(\mathrm{X}, \tau) \square \rightarrow(\mathrm{Y}, \sigma)$ be defined by $\mathrm{f}(\mathrm{a})$ $=c, f(b)=b$ and $f(c)=a$. Here the inverse image of the open set $\{a, c\}$ in $Y$ is $\square\{a, c\}$ in $X$ is sb*-open but not $\alpha \mathrm{g}$ - open. Therefore the defined function is $\mathrm{sb}^{*}$ continuous but not $\alpha \mathrm{g}$-continuous.

Remark 3.31: The following example shows that the $\mathrm{sb}^{*}$ - continuous function and $\mathrm{sg}$ - continuous function are independent

Example 3.32: Consider $\mathrm{X}=\mathrm{Y}=\square\{\mathrm{a}, \mathrm{b}, \mathrm{c}\}$ with $\tau=\{X$, $\varphi, \square\{a\},\{c\},\{a, c\}\}$ and $\sigma=\square\{Y, \varphi, \square\{a, c\}\}$. Let the function $\mathrm{f}:(\mathrm{X}, \tau) \square \rightarrow(\mathrm{Y}, \sigma)$ be defined by $\mathrm{f}(\mathrm{a})=\mathrm{b}$, $\mathrm{f}(\mathrm{b})=\mathrm{a}, \mathrm{f}(\mathrm{c})=\mathrm{c}$. Here the inverse image of the open set $\square\{a, c\}$ in $Y$ is $\square\{b, c\}$ in $X$ is sg-open set but not $\mathrm{sb}^{*}$ - open. Therefore the defined function is $\mathrm{sg}$ continuous but not $\mathrm{sb}^{*}$-continuous.

Example 3.33: Consider $\mathrm{X}=\mathrm{Y}=\{\mathrm{a}, \mathrm{b}, \mathrm{c}\}$ with $\tau=\{X$, $\varphi,\{a, c\}\}$ and $\sigma=\{Y, \varphi,\{a\},\{a, b\}\}$. Let the function $\mathrm{f}:(\mathrm{X}, \tau) \rightarrow$ $(\mathrm{Y}, \sigma)$ be defined by $\mathrm{f}(\mathrm{a})=\mathrm{c}, \mathrm{f}(\mathrm{b})=\mathrm{b}$ and $\mathrm{f}(\mathrm{c})=\mathrm{a}$. Here the inverse image of the open set $\{a, b\}$ in $Y$ is $\{b, c\}$ in $X$ is $\mathrm{sb}^{*}$ - open but not sg-open. Therefore the defined function is $\mathrm{sg}$ - continuous but not $\mathrm{sb}^{*}$-continuous.

Remark 3.34: The following example shows that the $\mathrm{sb}^{*}$ - continuous function and semi - continuous function are independent.

Example 3.35: Consider $\mathrm{X}=\mathrm{Y}=\{\mathrm{a}, \mathrm{b}, \mathrm{c}\}$ with $\tau=\{X$, $\varphi,\{a, c\}\}$ and $\sigma=\{Y, \varphi,\{a\},\{b\},\{a, b\}\}$. Let the function $\mathrm{f}:(\mathrm{X}, \tau) \rightarrow(\mathrm{Y}, \sigma)$ be defined by $\mathrm{f}(\mathrm{a})=\mathrm{a}, \mathrm{f}(\mathrm{b})=\mathrm{c}, \mathrm{f}(\mathrm{c})=\mathrm{b}$. Here the inverse image of the open set $\{a\}$ in $Y$ is $\{a\}$ in $X$ which is not semi open but it is $s^{*}$ - open. Therefore the defined function is $\mathrm{sb}^{*}$ - continuous but not semicontinuous.

Example 3.36: Consider $\mathrm{X}=\mathrm{Y}=\{\mathrm{a}, \mathrm{b}, \mathrm{c}\}$ with $\tau=\{X$, $\varphi,\{a\},\{c\},\{a, c\}\}$ and $\sigma=\{Y, \varphi,\{b, c\}\}$. Let the function $\mathrm{f}:(\mathrm{X}, \tau) \rightarrow(\mathrm{Y}, \sigma)$ be defined by $\mathrm{f}(\mathrm{a})=\mathrm{a}, \mathrm{f}(\mathrm{b})=\mathrm{c}$ and $\mathrm{f}(\mathrm{c})=\mathrm{b}$. Here the inverse image of the open set $\{b, c\}$ in $Y$ is $\{b, c\}$ in $X$ which is semi- open but not sb* - open. Therefore the defined function is semi - continuous but not $\mathrm{sb}^{*}$-continuous.

Remark 3.37: From the above results the diagram follows:

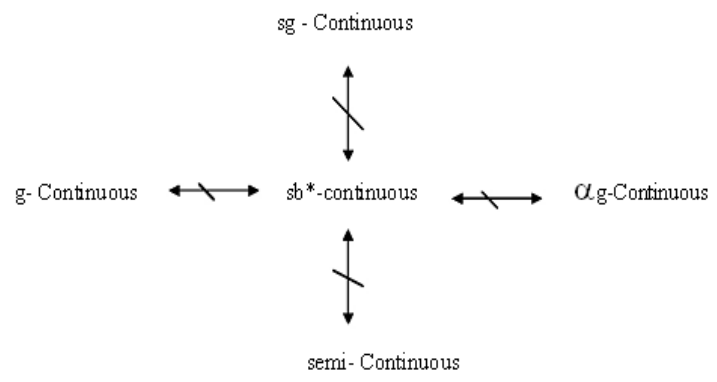




\section{STRONGLY $b^{*}$ - OPEN AND CLOSED MAPS}

In this section we introduce the new concept of $\mathrm{sb}^{*}$ closed maps and studied some of their properties

Definition 4.1: Let $X$ and $Y$ be a topological spaces. A map $\mathrm{f}: \mathrm{X} \rightarrow \mathrm{Y}$ is called strongly $\mathrm{b}^{*}$-closed (sb* - closed) map if the image of every closed set in $\mathrm{X}$ is $\mathrm{sb}^{*}$ - closed set in $\mathrm{Y}$.

Theorem 4.2: Every closed map is $s^{*}$-closed but not conversely.

Proof: Let $\mathrm{f}: \mathrm{X} \rightarrow \mathrm{Y}$ be closed map and $\mathrm{V}$ be a closed set in $\mathrm{X}$. Then $\mathrm{f}(\mathrm{V})$ is closed and hence $\mathrm{sb}^{*}$-closed in $\mathrm{Y}$. Thus $\mathrm{f}$ is $\mathrm{sb}^{*}$ - closed. The converse of the above theorem need not be true as seen from the following example.

Example 4.3: Consider $\mathrm{X}=\mathrm{Y}=\{\mathrm{a}, \mathrm{b}, \mathrm{c}\}, \tau=\{X$, $\varphi,\{a\}\}$ and $\sigma=\{Y, \varphi,\{a\},\{a, b\}\}$ and a map $\mathrm{f}: \mathrm{X} \rightarrow \mathrm{Y}$ be defined by $\mathrm{f}(\mathrm{a})=\mathrm{a}, \mathrm{f}(\mathrm{b})=\mathrm{f}(\mathrm{c})=\mathrm{b}$. This function $\mathrm{f}$ is sb*-closed but not closed as $f(\{b, c\})=\{b\}$ is not closed in $Y$.

Theorem 4.4: If a map $\mathrm{f}: \mathrm{X} \rightarrow \mathrm{Y}$ is continuous and $\mathrm{sb}^{*}$-closed, $A$ is $\mathrm{sb}^{*}$ - closed set of $\mathrm{X}$ then $\mathrm{f}(\mathrm{A})$ is $\mathrm{sb}^{*}$-closed in $\mathrm{Y}$.

Proof: Let $f(A) \subseteq O$, where $O$ is b-open set of $Y$. Since $f$ is continuous $\mathrm{f}^{-1}(\mathrm{O})$ is b-open set containing $A$. Hence $\operatorname{cl}(\operatorname{int}(\mathrm{A})) \subseteq \mathrm{f}^{-1}(\mathrm{O})$, as $\mathrm{A}$ is $\mathrm{sb}^{*}$-closed. Since $\mathrm{f}$ is $\mathrm{sb}^{*}$-closed $\mathrm{f}(\operatorname{cl}(\operatorname{int}(\mathrm{A})))$ is a $\mathrm{sb}^{*}$-closed set contained in the b-open set $\mathrm{O}$, which implies cl(int $\mathrm{f}(\mathrm{A})) \subseteq \mathrm{O}$. So, $\mathrm{f}(\mathrm{A})$ is sb* -open in $\mathrm{Y}$.

Theorem 4.5: A map $\mathrm{f}: \mathrm{X} \rightarrow \mathrm{Y}$ is sb*-closed if and only if for each subset $S$ of $Y$ and for each open set $U$ containing $\mathrm{f}^{-1}(\mathrm{~S})$ there is a sb*-open set $\mathrm{V}$ of $\mathrm{Y}$ such that $\mathrm{S} \subseteq \mathrm{V}^{*}$ and $\mathrm{f}^{-1}(V) \subseteq \mathrm{U}$.

Proof: Suppose $\mathrm{f}$ is $\mathrm{sb}^{*}$-closed. Let $\mathrm{S}$ be a subset of $\mathrm{Y}$ and $U$ be a open set of $X$ such that $\mathrm{f}^{-1}(\mathrm{~S}) \subseteq \mathrm{U} . \mathrm{V}=\mathrm{Y}-\mathrm{f}(\mathrm{X}-\mathrm{U})$ is a sb* - open set containing $S$ such that $\mathrm{f}^{-1}(V) \subseteq \mathrm{U}$.

For the converse, suppose that $\mathrm{F}$ is a closed set of $\mathrm{X}$. Then $\mathrm{f}^{-1}(\mathrm{Y}-\mathrm{f}(\mathrm{F})) \subseteq \mathrm{X}-\mathrm{F}$ and $\mathrm{X}-\mathrm{F}$ is open. By hypothesis, there is a sb*-open set $\mathrm{V}$ of $\mathrm{Y}$ such that $\mathrm{Y}-\mathrm{f}(\mathrm{F}) \subseteq \mathrm{V}^{*}$ and $\mathrm{f}^{-1}(\mathrm{~V}) \subseteq \mathrm{X}-\mathrm{F}$. Therefore $\mathrm{F} \subseteq X-f^{-1}(\mathrm{~V})$. Hence $\mathrm{Y}-\mathrm{V} \subseteq f(\mathrm{~F}) \subseteq \mathrm{f}\left(\mathrm{X}-\mathrm{f}^{-1}(\mathrm{~V})\right) \subseteq \mathrm{Y}-\mathrm{V}$. Which implies $f(F)=Y-V$. Since $Y-V$ is sb*-closed, $f(F)$ is $\mathrm{sb}^{*}$-closed and thus $\mathrm{f}$ is $\mathrm{sb}^{*}$-closed map.

Theorem 4.7: If a map $\mathrm{f}: \mathrm{X} \rightarrow \mathrm{Y}$ is closed and a map g: $\mathrm{Y} \rightarrow \mathrm{Z}$ is sb*-closed then gof: $\mathrm{X} \rightarrow \mathrm{Z}$ is sb*-closed.

Proof: Let $V$ be a closed set in $X$. Since $f: X \rightarrow Y$ is closed, $\mathrm{f}(\mathrm{V})$ is closed set in $\mathrm{Y}$. Since $\mathrm{g}: \mathrm{Y} \rightarrow \mathrm{Z}$ is $\mathrm{sb}^{*}$ - closed, $\mathrm{h}(\mathrm{f}(\mathrm{V}))$ is $s b^{*}$ - closed set in $\mathrm{Z}$. Therefore $(\mathrm{g} \circ \mathrm{f}): \mathrm{X} \rightarrow \mathrm{Z}$ is sb ${ }^{*}$ - closed map.

\section{REFERENCES}

[1] M E Abd El- Monsef S N El - Deeb and R A Mahmoud, $\beta$ - continuous mapping, Bull. Fac.Sci.Assiut Univ.A 12 (1)(1983), 77-90.

[2] Balachandran K, Sundaram $\mathrm{P}$ and Maki H, On Generalized Continuous maps in Topological spaces, Mem. Fac.Sci.Kochi.Univ.Math.12(1991).

[3] Biswas N, On characterizations of semi-continuous functions, Atti Acad. Naz. Lincei
Rend.Cl.Sci.Fis.Mat.Natur.,48(1970), 399-402.

[4] Devi R, Balachandran and Maki H, On Generalized $\alpha$ continuous maps and $\alpha$-generalized continuous maps, For East J. Math Sci. (Special Volume Part I), (1997), 1- 15.

[5] Dontchev J, Contra - continuous functions and strongly s - closed spaces, Internat. J Mat. Sci 19(1996), $303-310$.

[6] Dontchev J, Ganster M and Reilly I L, More on almost s- continuous, Indian. J. Math.41(1999), 139 - 146.

[7] Dunham. W, $\mathrm{T}_{1} / 2$ - spaces, Kyungpook math. J.17(1977), 161-169.

[8] Dunham. W and Levine. N, Further results on generalized closed sets in topology, Kyungpook math.J.20.(1980),165-175.

[9] Erdal Eckici, Almost contra - pre continuous functions, Bull. Malaysian Math. Sc. Soc.(Second Series)27(2004)53-65

[10] Ekici. E and Caldas M, Slightly $\gamma$-continuous functions, Bol. Soc. Parana. Mat(3) 22(2004),2,63-74.

[11] Jafari S and Noiri T, On contra - pre continuous functions, Bull. Malaysian Math. Sc. Soc.25(2002),115-128.

[12] Levine. N, Generalised closed sets in Topology, Rend. Circ. Mat. Palerno (2), 19 (1970), 89 - 96.

[13] Levine. N, Strong continuity in topological spaces, Amer.Math. Monthly.67(1960)269.

[14] Mashhour A S, Hasanain I A and El-Deeb S N , $\alpha$ continuous and $\alpha$-open mappings, Acta Math Hungar, 41(1983), 213-218.

[15] Munshi B M and Bassan D S., Super continuous mappings, Indian J. Pure Appl. Maths, 13(1982), 229 236.

[16] Nagaveni N , Studies on generalization of homeomorphisms in topological spaces, Ph.D, Thesis, Bharathiar University, Coimbatore(1999).

[17] Noiri T, Ahmeeed B and Khan M, Almost s- continuous functions, Kyungpook Math. J. 35(1995)311- 322.

[18] Noiri T, super -continuity and some strong forms of continuity Indian J. Pure. Appl. Math., 15(1984), 241250 .

[19] Poongothai A and Parimelazhagan R, sb*-closed sets in Topological spaces, Int. Journal of Math. Analysis Vol. 6, 2012, no.47, 2325-2333.

[20] Reilly I L and Vamanamurthy M K, On supercontinuous mappings, Indian J. Pure. Appl. Math. 14(1983), 767-772.

[21] Sundaram P, Studies on Generalizations of continuous maps in topological spaces, Ph.D, thesis, Bharathiar University, Coimbatore 1991.

[22] Sundaram P and Sheik John M, Weakly closed sets and weakly continuous maps in topological spaces, Proc.82nd session of the Indian Science Congress, Calcutta, 1995, p -49. 